\title{
Study of the combustion efficiency of polymers using a pyrolysis-combustion flow calorimeter
}

\author{
Rodolphe Sonnier*, Belkacem Otazaghine, Laurent Ferry, José-Marie Lopez-Cuesta
}

CMGD Material Center, Ecole des Mines d'Alès, 6, Avenue de Clavières, 30100 Alès, France

\begin{abstract}
A B S T R A C T
The combustion efficiency of various polymeric materials was studied using a pyrolysis-combustion flow calorimeter (PCFC). Decreasing the combustion temperature in a PCFC leads to partial combustion and lower heat release rates. Combustion efficiency versus combustion temperature was modeled using a phenomenological equation and model parameters were related to the chemical structures of eight pure polymers. The flame inhibition effect was evaluated for two classical approaches in flame retardancy by plotting the combustion efficiency versus the combustion temperature. In the first one (the reactive approach), polystyrenes with different chemical groups substituted on the aromatic ring were studied. In the second one (the additive approach), three well-known flame retardants were incorporated into an ABS matrix: ammonium polyphosphate, tetrabromobisphenol A (TBBA), and a TBBA/antimony trioxide system. Results confirm the flame inhibition effect of halogenated compounds in both approaches. Finally, a correlation between peaks of heat release rate (pHRR) in a cone calorimeter and in a PCFC was attempted. Predicting pHRR in a cone calorimeter using a PCFC appears possible when no barrier effect is expected, if PCFC tests are carried out at a precise combustion temperature, for which the combustion efficiencies in both tests are the same.
\end{abstract}

Keywords:

PCFC

Cone calorimeter

Flame inhibition

Combustion efficiency

Flame retardancy

\section{Introduction}

When exposed to an intense heat source, polymers undergo thermal or thermo-oxidative decomposition, leading to release of highly combustible gases. The complete combustion of these gases in the presence of oxygen releases heat, water, and carbon dioxide if the polymer contains only $\mathrm{C}, \mathrm{H}$, and $\mathrm{O}$ atoms. Nevertheless, combustion is generally only partial and released heat is lower than expected. Combustion efficiency is calculated as the ratio of the real heat release to the maximum heat release (i.e., when combustion is complete).

The main mode of action of halogenated flame retardants is flame inhibition, i.e., the decrease in combustion efficiency. Flame inhibition is partly due to physical effects (dilution and heat capacity, which lead to the cooling of the flame) and partly due to chemical effects (scavenging of highly reactive radicals $\mathrm{H}^{\circ}, \mathrm{OH}^{\cdot}$ that attack the hydrocarbons [1-3]). Halogenated molecules (such as $\mathrm{HBr}$ ) react in the gaseous phase by trapping reactive radicals to give less reactive radicals [1]:

$$
\begin{aligned}
& \mathrm{RX} \rightarrow \mathrm{R}^{\circ}+\mathrm{X}^{\circ}(\mathrm{X}=\mathrm{Br} \text { or } \mathrm{Cl}) \\
& \mathrm{X}^{\circ}+\mathrm{RH} \rightarrow \mathrm{R}^{\circ}+\mathrm{HX} \\
& \\
& \quad \text { * Corresponding author. } \\
& \quad \text { E-mail address: rodolphe.sonnier@mines-ales.fr (R. Sonnier). }
\end{aligned}
$$

\footnotetext{
* Corresponding author.

E-mail address: rodolphe.sonnier@mines-ales.fr (R. Sonnier).
}

$\mathrm{HX}+\mathrm{H}^{\circ} \rightarrow \mathrm{H}_{2}+\mathrm{X}^{\circ}$

$\mathrm{HX}+\mathrm{OH}^{\circ} \rightarrow \mathrm{H}_{2} \mathrm{O}+\mathrm{X}^{\circ}$.

Therefore, some combustible molecules are not fully oxidized, $\mathrm{CO}$ is produced (rather than $\mathrm{CO}_{2}$ ), and the heat release is significantly reduced. The efficiency of various compounds in flame inhibition was estimated experimentally or by calculations [1-4]. This efficiency is mainly dependent on specific atoms. Metallic compounds containing $\mathrm{Fe}, \mathrm{Pb}$, or $\mathrm{Cr}$ are the most effective [1]. Intrinsic inhibition indices were calculated using a Van Krevelen approach for different atoms: $\mathrm{C}, \mathrm{H}, \mathrm{F}, \mathrm{Cl}, \mathrm{Br}$, and I. The last two were found to be the most effective [3]. It was highlighted that $\mathrm{CF}_{3} \mathrm{Br}$ and $\mathrm{CF}_{3} \mathrm{I}$ inhibit flame by chemical action, while other studied additives (fluorinated additives) act mainly through physical effects. Some phosphorus flame retardants could also have a similar action, but their main mode of action is generally considered as char promotion in the condensed phase. Another important characteristic for an efficient flame inhibitor is its ability to be regenerated during the combustion process [2,3].

The pyrolysis-combustion flow calorimeter (PCFC) is an apparatus developed approximately 12 years ago to measure some important flammability parameters of polymers through nonflaming combustion [5]. Since it needs only milligrams of material, it is a powerful method for studying polymers synthesized in the laboratory in small amounts. Some research teams attempted to use 
PCFC as a screening tool before performing cone calorimeter tests, which need a greater amount of material [6-8]. But the correlation between the cone calorimeter and the PCFC results is not general, for three main reasons [9]. The first is the barrier effect, which is not efficient in the PCFC, in contrast to the cone calorimeter. The barrier effect becomes effective when an insulating layer could protect the underlying material from the heat source. This layer may be composed of char and/or mineral particles and should be thermally stable. The second is related to thermal stability. Two polymers could exhibit similar peaks of heat release rate but different degradation temperatures in PCFC. In this case, cone calorimeter results could be very different. The third reason is that the combustion is complete in the PCFC standard test while the combustion efficiency could be less than 1 in the cone calorimeter test, even if this test is carried out under well-ventilated conditions.
Nevertheless, it is possible to monitor the conditions (oxygen rate and temperature) in the PCFC combustion chamber to decrease the combustion efficiency, as presented in an article of Schartel et al. [10]. The decoupling between pyrolysis and combustion in the PCFC allows changing the conditions of combustion without modifying the pyrolysis of the sample. This possibility should allow studying the flame inhibition of halogenated flame retardants. But to the best of our knowledge, this possibility has never been exploited. We believe that only the chemical component of flame inhibition could be studied, since the combustion temperature is kept fixed during the test.

In the present article, the combustion temperature in the PCFC was monitored to study the change in combustion efficiency for various polymeric materials. This method was developed to know the role of different elements $(\mathrm{Cl}, \mathrm{Br}, \mathrm{P})$ as efficient flame retar-

Table 1

Chemical composition of the materials studied.

\begin{tabular}{|c|c|c|c|}
\hline Series & Designation & Name & Chemical structure \\
\hline \multirow[t]{6}{*}{ A } & PS & Polystyrene & \\
\hline & $\mathrm{PS}-\mathrm{CH}_{3}$ & Poly(4-methylstyrene) & \\
\hline & $\mathrm{PS}-\mathrm{OCH}_{3}$ & Poly(4-methoxystyrene) & \\
\hline & $\mathrm{PS}-\mathrm{Cl}$ & Poly(4-chlorostyrene) & \\
\hline & $\mathrm{PS}-\mathrm{Br}$ & Poly(4-bromostyrene) & \\
\hline & PS-P & Poly(diethyl vinylbenzylphosphonate) & \\
\hline \multirow[t]{9}{*}{ B } & LDPE & Riblene FL20 (Polimeri Europa) & \\
\hline & PMMA & Altuglas V825T (Arkema) & \\
\hline & PS & Lacqrene 1340 (Arkema) & \\
\hline & ABS & Terluran GP22 (BASF) & \\
\hline & PA6 & Technyl C216 (Rhodia) & \\
\hline & PA11 & Rilsan (Arkema) & \\
\hline & EVA (28 wt\% vinyl acetate) & Evatane 2805 (Arkema) & \\
\hline & PVC & EVC Compound & \\
\hline & & & FR content (wt\%) \\
\hline \multirow[t]{3}{*}{ C } & $\mathrm{ABS}+\mathrm{APP}$ & Terluran GP22 (BASF) + AP423 (CLARIANT) & $3.1,7.9,15.7,31.5,40$ \\
\hline & $\mathrm{ABS}+\mathrm{TBBA}$ & Terluran GP22 (BASF) + tetrabromobisphenol A & $1.6,15.6,31$ \\
\hline & $\mathrm{ABS}+\mathrm{TBBA} / \mathrm{Sb}_{2} \mathrm{O}_{3}$ & Terluran GP22 (BASF) + tetrabromobisphenol A/antimony trioxide & $1.7 / 0.6,4.2 / 1.5,8.5 / 3,13.6 / 4.8,18.6 / 6.6$ \\
\hline
\end{tabular}


dants. Two classical approaches in flame retardancy were studied: The first is the reactive approach, where flame retardant groups are grafted onto the macromolecular backbone. The second is the additive approach, where flame retardant compounds are physically incorporated into the polymer. Finally, an attempt was made to predict the combustion efficiency in the cone calorimeter from PCFC results.

\section{Experimental}

Three series of materials were studied (listed in Table 1). Series A gathers polystyrenes with various substituent groups in the para position on phenyl rings. Polystyrene is Lacqrene 1340. Poly-(4-methylstyrene, 4-methoxystyrene, 4-chlorostyrene, or 4-bromostyrene) is provided by Aldrich. Poly(diethyl vinylbenzylphosphonate) was synthesized in the laboratory. For this polymer, the substituent group is partially in the meta and partially in the para position. Series B gathers various pure commercial polymers. Series $C$ gathers acrylonitrile butadiene styrene (ABS) polymers containing three kinds of flame retardant additives in various quantities: ammonium polyphosphate (AP423 from Clariant), tetrabromobisphenol A (TBBA), and a system combining TBBA and antimony trioxide $\left(\mathrm{Sb}_{2} \mathrm{O}_{3}\right)$. The ratio of TBBA to $\mathrm{Sb}_{2} \mathrm{O}_{3}$ was fixed to 2.8. This ratio is in the typical range for flame retarded styrenic polymers such as high-impact polystyrene and ABS $[11,12]$. The compounds were prepared using a Clextral BC21 twin-screw extruder. Squared sheets of thickness $4 \mathrm{~mm}$ for cone calorimeter tests were injection-molded using a Sandretto 95-ton press. Processing temperatures were typically fixed to $200^{\circ} \mathrm{C}$.

Thermogravimetric analyses (TGA) were performed using a Pyris-1 Perkin-Elmer apparatus. Samples of $10( \pm 2) \mathrm{mg}$ were heated under a nitrogen flow at a heating rate equal to $10^{\circ} \mathrm{C} / \mathrm{min}$ from ambient temperature to $750{ }^{\circ} \mathrm{C}$.

PCFC tests were performed using fire testing technology apparatus (Fig. 1) according to the ASTM D7309 [13]. A sample of 2 $( \pm 1) \mathrm{mg}$ was heated under nitrogen flow to $750{ }^{\circ} \mathrm{C}$ at a heating rate equal to $1 \mathrm{~K} / \mathrm{s}$. Gases are extracted and sent to a combustion chamber in the presence of a $\mathrm{N}_{2} / \mathrm{O}_{2} 80 / 20$ flow. The flow rate is fixed to $100 \mathrm{~cm}^{3} / \mathrm{min}$. At this flow rate, the residence time of gases in the combustor is approximately $10 \mathrm{~s}$. All details about the PCFC construction can be found elsewhere [5]. It should be noted that the combustor was designed to ensure complete oxidation of pyrolysis products at a combustion temperature fixed to $900{ }^{\circ} \mathrm{C}$.

For each experiment, the sample weight was chosen carefully to ensure that $\mathrm{O}_{2}$ is always in excess. The temperature of combustion was monitored between 900 and $600{ }^{\circ} \mathrm{C}$. Combustion efficiency at a temperature $T$ is calculated as follows:

$\chi(T)=\left(\Delta \mathrm{O}_{2}\right.$ at the temperature $\left.T\right) /\left(\Delta \mathrm{O}_{2}\right.$ at $\left.900^{\circ} \mathrm{C}\right)$,

where $\Delta \mathrm{O}_{2}$ at the temperature $T$ is the mass or volume of oxygen consumed at the combustor set point temperature $T$, and $\Delta \mathrm{O}_{2}$ at

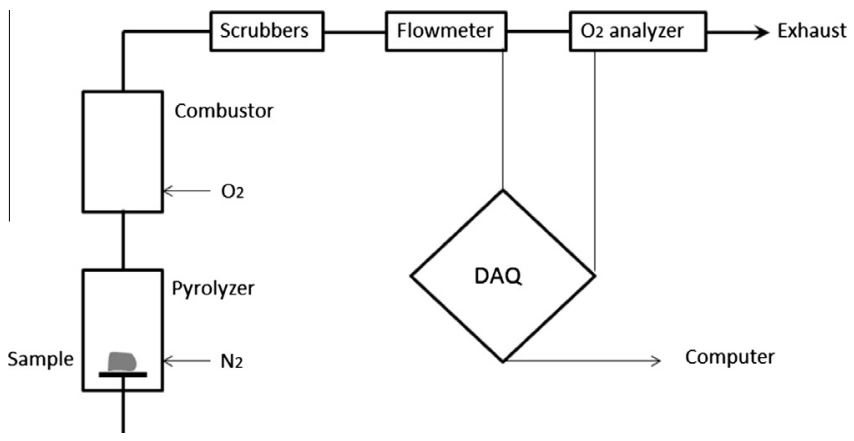

Fig. 1. Schema of pyrolysis-combustion flow calorimeter (from [9]).

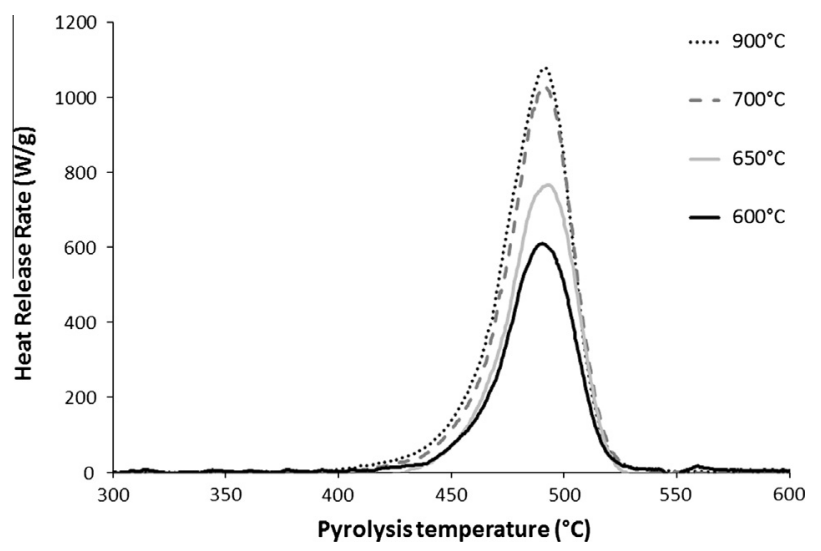

Fig. 2. Heat release rate curves measured by PCFC for LDPE at various combustion temperatures $\left(900,700,65,0\right.$ and $\left.600{ }^{\circ} \mathrm{C}\right)$.

$900{ }^{\circ} \mathrm{C}$ is the oxygen consumed by combustion of the pyrolysis gases at $T=900{ }^{\circ} \mathrm{C}$. As said previously, $900{ }^{\circ} \mathrm{C}$ is generally enough to ensure complete combustion.

The heat release rate is calculated from the oxygen consumption according to Huggett's relation ( $1 \mathrm{~kg}$ of consumed oxygen corresponds to $13.1 \mathrm{MJ}$ of released heat) [14]. Total heat release is equal to the area under the curve plotting the heat release rate versus the pyrolysis temperature. Therefore, combustion efficiency is practically calculated as follows:

$$
\begin{aligned}
\chi(T)= & (\text { total heat release at the temperature } T) \\
& /\left(\text { total heat release at } 900{ }^{\circ} \mathrm{C}\right) .
\end{aligned}
$$

Eqs. (2A) and (2B) are equivalent in this case.

It should be recalled that the pyrolysis conditions were never changed. Only the combustion efficiency of the gases obtained by pyrolysis was affected when the combustion temperature was modified. As an example, the heat release rate over the whole range of pyrolysis temperatures is given in Fig. 2 for LDPE at various combustion temperatures. While no change could be observed between 900 and $700{ }^{\circ} \mathrm{C}$, the heat release rate decreases significantly below the latter temperature.

Cone calorimeter tests were performed using a FTT apparatus according to the ISO 5660 standard. Irradiance was fixed at $50 \mathrm{~kW} / \mathrm{m}^{2}$. Ignition was piloted using a spark igniter. Only formulations from series $B$ and $C$ were tested (amounts of polystyrenes from series A were insufficient). All formulations were duplicated.

Py-GC/MS analyses were performed with a Pyroprobe 5000 pyrolyzer equipped with a CDS Analytical for flash pyrolysis in a helium environment. The samples were heated to $600^{\circ} \mathrm{C}$. The heating rate was close to $20^{\circ} \mathrm{C} / \mathrm{ms}$. For PS-P, an additional experiment was carried out: the sample was heated in two steps, to $400{ }^{\circ} \mathrm{C}$ and then to $600{ }^{\circ} \mathrm{C}$. Each temperature was held for $15 \mathrm{~s}$; then the gases were drawn toward the gas chromatograph for $5 \mathrm{~min}$. The Pyroprobe 5000 is interfaced with a Varian $450-$ GC gas chromatograph. In the oven the initial temperature of $70^{\circ} \mathrm{C}$ was raised to $250{ }^{\circ} \mathrm{C}$ at $10^{\circ} \mathrm{C} / \mathrm{min}$. The column was a Varian Vf-5ms capillary column $(30 \mathrm{~m} \times 0.25 \mathrm{~mm})$ and helium $(1 \mathrm{~mL} / \mathrm{min})$ was used as the carrier gas. The gases were introduced from the GC transfer line to the ion trap analyzer of the Varian 240-MS mass spectrometer through a direct-coupled capillary column. Initial sample weight was less than $1 \mathrm{mg}$ for each experiment.

\section{Results and discussion}

The main values obtained in the PCFC for all studied materials are listed in Table 2. HRC, THR, and temperature at pHRR are given 
Table 2

PCFC results for all tested materials.

\begin{tabular}{|c|c|c|c|c|c|c|c|}
\hline \multirow[t]{2}{*}{ Combustion temperature $\left({ }^{\circ} \mathrm{C}\right)$} & \multirow{2}{*}{$\begin{array}{l}\mathrm{HRC}(\mathrm{J} / \mathrm{g} \mathrm{K}) \\
900{ }^{\circ} \mathrm{C}\end{array}$} & \multirow{2}{*}{$\begin{array}{l}\text { THR }(\mathrm{kJ} / \mathrm{g}) \\
900{ }^{\circ} \mathrm{C}\end{array}$} & \multirow{2}{*}{$\begin{array}{l}\text { Temp. at pHRR }\left({ }^{\circ} \mathrm{C}\right) \\
900{ }^{\circ} \mathrm{C}\end{array}$} & \multicolumn{3}{|l|}{$X$} & \multirow[t]{2}{*}{ Isoconversion temperature $\left({ }^{\circ} \mathrm{C}\right)$} \\
\hline & & & & $600^{\circ} \mathrm{C}$ & $650^{\circ} \mathrm{C}$ & $700^{\circ} \mathrm{C}$ & \\
\hline \multicolumn{8}{|l|}{ Series A } \\
\hline PS & 840 & 34.7 & 434 & 0.21 & 0.41 & 0.88 & 696 \\
\hline PS- $\mathrm{CH}_{3}$ & 684 & 35.8 & 435 & 0.17 & 0.46 & 0.96 & NA \\
\hline PS-OCH ${ }_{3}$ & 653 & 29.8 & 432 & 0.26 & 0.48 & 0.89 & NA \\
\hline $\mathrm{PS}-\mathrm{Cl}$ & 466 & 23.8 & 433 & 0.11 & 0.30 & 0.63 & NA \\
\hline $\mathrm{PS}-\mathrm{Br}^{\mathrm{a}}$ & 190 & 12.3 & 424 & 0.28 & 0.34 & 0.66 & NA \\
\hline PS-P & & 15.5 & & 0.48 & 0.67 & 0.93 & NA \\
\hline PS-P first peak & 184 & 10 & 345 & 0.54 & 0.71 & 0.93 & NA \\
\hline PS-P second peak & 155 & 5.5 & 487 & 0.36 & 0.6 & 0.93 & NA \\
\hline \multicolumn{8}{|l|}{ Series $B$} \\
\hline ABS & 541 & 34.1 & 467 & 0.32 & 0.57 & 0.95 & 671 \\
\hline PMMA & 419 & 22.8 & 390 & 0.40 & 0.73 & 0.86 & 719 \\
\hline PA6 & 525 & 28.5 & 474 & 0.46 & 0.71 & 0.88 & NA \\
\hline PA11 & 709 & 31.1 & 450 & 0.50 & 0.77 & 0.93 & 717 \\
\hline LDPE & 1092 & 41.1 & 490 & 0.57 & 0.75 & 0.93 & NA \\
\hline EVA28 & 751 & 36.6 & 483 & 0.56 & 0.73 & 0.84 & 671 \\
\hline PVC & 179 & 15 & 463 & 0.30 & 0.54 & 0.65 & 663 \\
\hline \multicolumn{8}{|l|}{ Series $C$} \\
\hline ABS $1.6 \%$ TBBA & 570 & 32.9 & 466 & NA & 0.67 & 0.90 & 669 \\
\hline ABS $15.1 \%$ TBBA & 434 & 29.7 & 453 & 0.25 & 0.60 & 0.80 & 648 \\
\hline ABS $31 \%$ TBBA $^{\mathrm{b}}$ & 321 & 23.8 & 453 & NA & 0.59 & 0.86 & 640 \\
\hline ABS $1.7 \%$ TBBA $0.6 \% \mathrm{Sb}_{2} \mathrm{O}_{3}$ & 595 & 36.2 & 465 & 0.22 & 0.67 & 0.85 & 683 \\
\hline ABS $4.3 \%$ TBBA $1.5 \% \mathrm{Sb}_{2} \mathrm{O}_{3}$ & 571 & 32.9 & 465 & NA & 0.67 & 0.92 & 663 \\
\hline ABS $8.5 \%$ TBBA $3 \% \mathrm{Sb}_{2} \mathrm{O}_{3}$ & 483 & 30.9 & 462 & 0.28 & 0.62 & 0.92 & 644 \\
\hline ABS $13.6 \%$ TBBA $4.8 \% \mathrm{Sb}_{2} \mathrm{O}_{3}$ & 406 & 27.9 & 463 & 0.26 & 0.65 & 0.87 & 627 \\
\hline ABS $18.6 \%$ TBBA $4.8 \% \mathrm{Sb}_{2} \mathrm{O}_{3}{ }^{\mathrm{b}}$ & 360 & 26.5 & 462 & 0.23 & 0.58 & 0.86 & 623 \\
\hline ABS $3.1 \%$ APP & 579 & 32.5 & 463 & NA & 0.69 & 0.94 & 665 \\
\hline ABS $7.9 \%$ APP & 548 & 30.8 & 460 & NA & 0.75 & 0.96 & 666 \\
\hline ABS $15.7 \%$ APP & 478 & 27.5 & 458 & NA & 0.81 & 0.99 & 666 \\
\hline ABS $31.5 \%$ APP & 391 & 23.4 & 458 & 0.27 & 0.69 & 0.92 & 664 \\
\hline ABS $40 \%$ APP & 342 & 20.6 & 466 & NA & 0.78 & 0.98 & 663 \\
\hline
\end{tabular}

a Incomplete combustion at $900{ }^{\circ} \mathrm{C}$.

b Possible incomplete combustion at $900^{\circ} \mathrm{C}$.

for a combustion temperature set to $900{ }^{\circ} \mathrm{C}$. Combustion efficiencies are determined for combustion temperatures set to 600,650 , and $700{ }^{\circ} \mathrm{C}$.

\subsection{Combustion efficiency of series A: roles of various chemical groups} in the flame inhibition effect

This series was studied to evaluate the effect of various chemical groups grafted onto a polystyrene backbone on the combustion efficiency.

The presence of different groups on the aromatic ring of polystyrene modifies the THR for complete combustion. Indeed, these groups modify the composition of the combustible gaseous phase and change energies released by combustion (Fig. 3). Moreover,

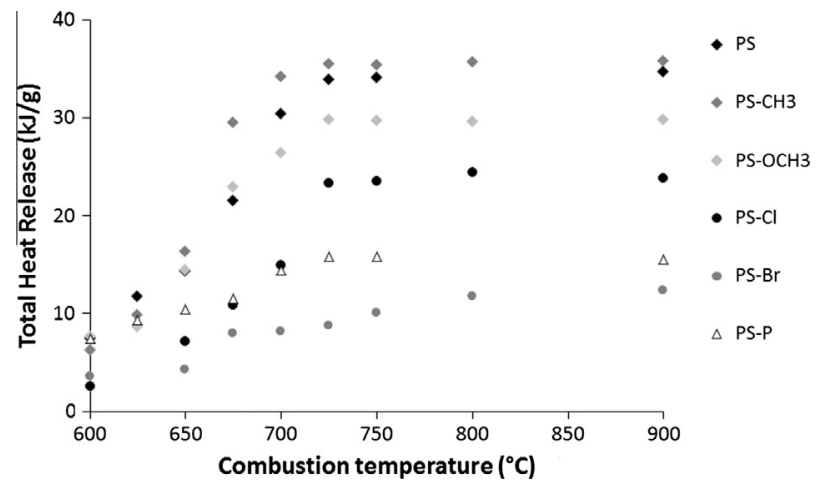

Fig. 3. THR of various functionalized polystyrenes measured by PCFC for different combustion temperatures. for the PS-P sample a high char content (36.3 wt\%, measured using thermogravimetric analysis) was obtained and explains the low THR value. For the other functionalized polystyrenes, the char formation was negligible (less than $2.5 \mathrm{wt} \%$ ).

Figure 4 shows the change in combustion efficiency with combustion temperature for the different functionalized polystyrenes. PS, PS- $\mathrm{CH}_{3}$, and $\mathrm{PS}-\mathrm{OCH}_{3}$ exhibit a same tendency, with a decrease of combustion efficiency below $725^{\circ} \mathrm{C}$. At $650{ }^{\circ} \mathrm{C}$, the combustion efficiency is similar for these polymers $(0.41-0.48)$. For the PS-Br, sample the decrease of combustion efficiency is observed at higher temperatures (between 750 and $800{ }^{\circ} \mathrm{C}$ ). The value is stable between 675 and $700{ }^{\circ} \mathrm{C}(0.65)$ and decreases further below $675^{\circ} \mathrm{C}$. Nevertheless, it should be noticed that the combustion efficiency curve does not show any plateau at high temperature: therefore, it is not possible to conclude that the combustion is

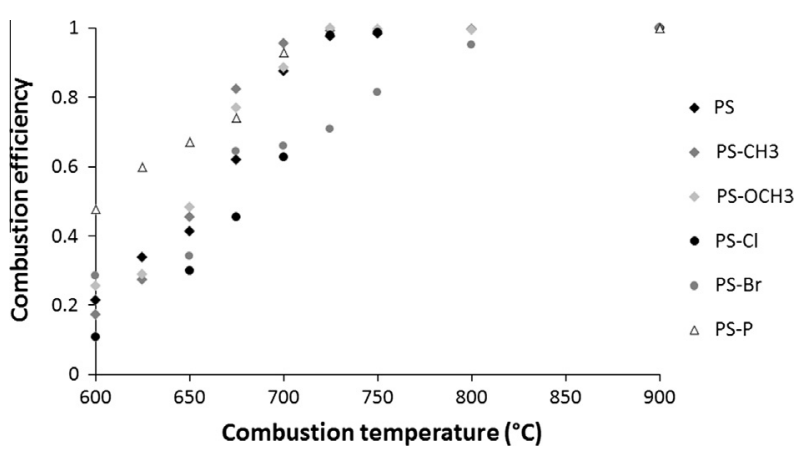

Fig. 4. Combustion efficiency of various polystyrenes measured by PCFC at different combustion temperatures. 
complete at $900{ }^{\circ} \mathrm{C}$ for PS-Br. A FTIR analysis of gases released after combustion at $900{ }^{\circ} \mathrm{C}$ confirms the presence of CO; i.e., some gases are not fully oxidized (data not shown). This result is not in agreement with the work of Lyon and Walters [15], which showed that the oxidation of highly brominated compounds is complete (99\%) in $10 \mathrm{~s}$ at $900{ }^{\circ} \mathrm{C}$ in PCFC. In our case, the combustion efficiency at a lower temperature than $900{ }^{\circ} \mathrm{C}$ is overestimated. For the PS$\mathrm{Cl}$ sample, the critical temperature is intermediate $\left(725-750{ }^{\circ} \mathrm{C}\right)$, but this decrease is faster: the combustion efficiency is close to 0.6 at $700{ }^{\circ} \mathrm{C}, 0.3$ at $650{ }^{\circ} \mathrm{C}$, and 0.1 at $600{ }^{\circ} \mathrm{C}$. These results are in agreement with the well-known flame inhibition effect of the halogens. It seems that gases released from pyrolysis of halogenated polymers need a higher temperature for total combustion in presence of oxygen.

Unlike the other modified polystyrenes, PS-P decomposes in several steps. Figure 5 shows the mass loss rate of the different modified polystyrenes measured by thermogravimetric analysis. Figure 6 shows the mass loss rate (measured in TGA) and the heat release rate (measured in PCFC for a combustion temperature of $900{ }^{\circ} \mathrm{C}$ ) of PS-P. Samples undergo linear heating under nitrogen flow in TGA and PCFC. Therefore the curves are similar in both analyses for the same formulation. Nevertheless the temperature value of the different peaks is slightly shifted between TGA and PCFC analyses because the heating rate is not the same $\left(10^{\circ} \mathrm{C} /\right.$ min in thermogravimetric analysis, $60^{\circ} \mathrm{C} / \mathrm{min}$ in PCFC). It could be considered that PS-P degrades in two main steps: between 150 and $380{ }^{\circ} \mathrm{C}$ and between 420 and $570{ }^{\circ} \mathrm{C}$. While the mass loss is similar for both steps (30-33 wt\%), the heat release (i.e., the area

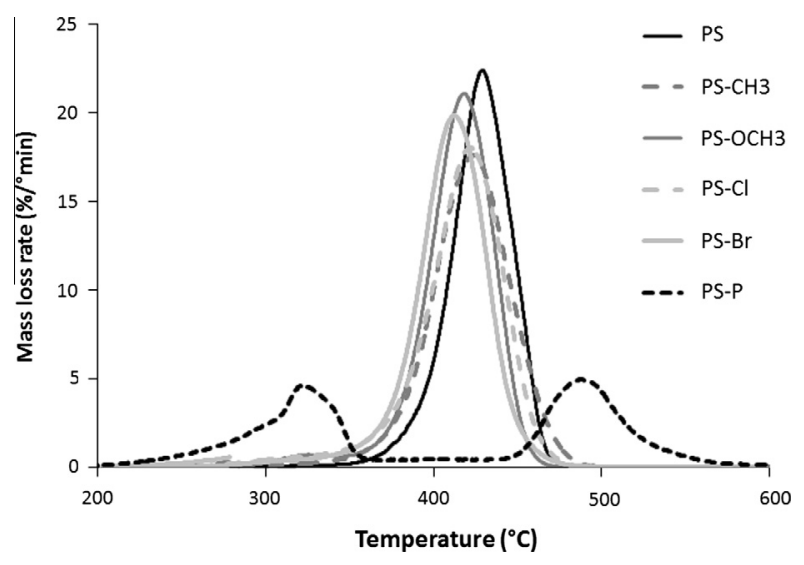

Fig. 5. Mass loss rate of the different polystyrenes measured by thermogravimetric analysis (nitrogen flow, $10^{\circ} \mathrm{C} / \mathrm{min}$ ).

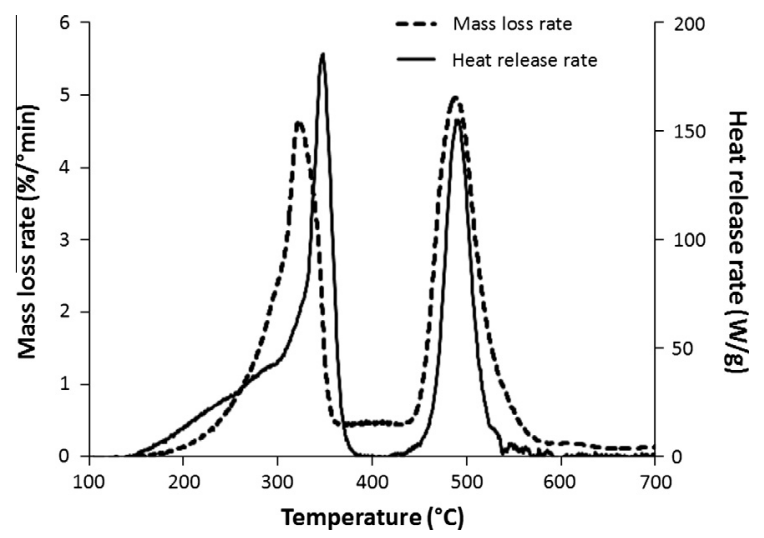

Fig. 6. Mass loss rate and heat release rate (at a combustion temperature $90{ }^{\circ} \mathrm{C}$ ) of PS-P.

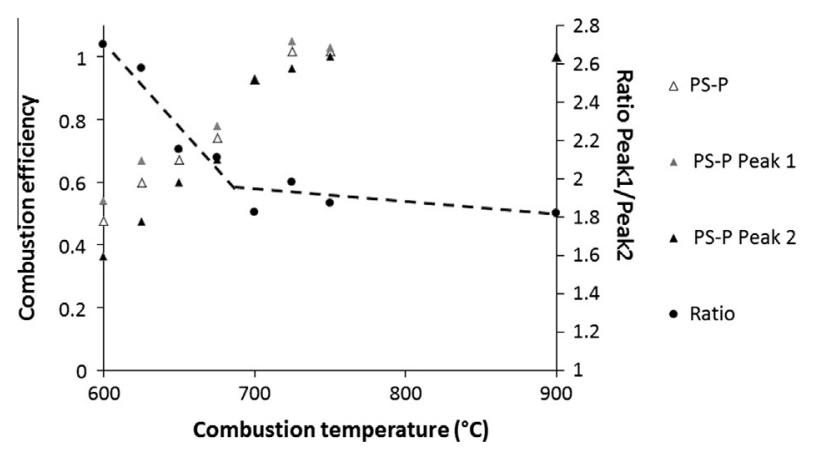

Fig. 7. Combustion efficiency of PS-P, first and second peaks of degradation and ratio between the heat releases of both peaks.

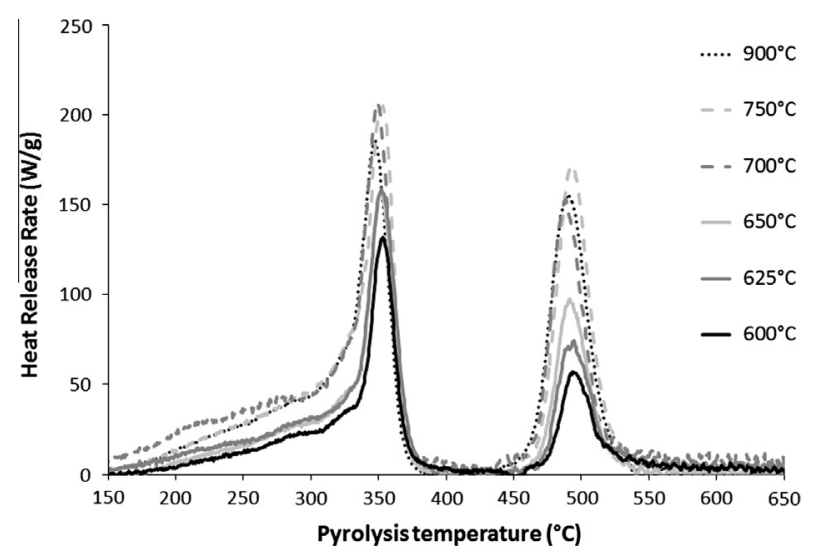

Fig. 8. Heat release rate of PS-P measured by PCFC for various combustion temperatures.

under the peak of heat release rate) is significantly different: $10 \mathrm{~kJ} /$ $\mathrm{g}$ and $5.5 \mathrm{~kJ} / \mathrm{g}$, respectively, for the first and second steps. Therefore, the effective heat of combustion (EHC, defined as the THR divided by the mass loss, i.e., the mass of volatiles released for each step separately) is strongly different for the two steps: 32.5 and $16.9 \mathrm{~kJ} / \mathrm{g}$, respectively, for the first and the second steps. This difference is due to the different natures of the released gases during the two steps.

The combustion efficiency of each step of degradation (PS-P peak 1 and PS-P peak 2) was calculated as a function of combustion temperature and compared with the global combustion efficiency of PS-P (Fig. 7). The ratio between the heat releases of the first and second peaks is also shown. The combustion efficiency starts decreasing below $725^{\circ} \mathrm{C}$. The decrease is faster for the second peak and its combustion efficiency is only 0.36 at $600{ }^{\circ} \mathrm{C}$, while the value for the first peak is 0.54 at the same combustion temperature. Therefore, the ratio between the heat release of the two peaks increases progressively from 1.8 to 2.7 when the combustion temperature decreases. The increase of this ratio is due to the gases released during the second step, which need higher temperatures to undergo total oxidation. Figure 8 shows clearly the faster decrease of the heat release corresponding to the second degradation step. This difference of evolution for the two peaks also proves the difference of the gases released by the two degradation steps.

Py-GC/MS analyses (Fig. 9) confirm the previous conclusions. The flash pyrolysis at $600{ }^{\circ} \mathrm{C}$ (i.e., at a temperature much higher than the degradation temperature) leads to various gases according to the chemical structure of the polymer. In most cases the molecules formed by pyrolysis of the modified polystyrenes are products of depolymerization. The poly(4-bromostyrene) and the poly(4-chlorostyrene) release large amounts of halogenated 

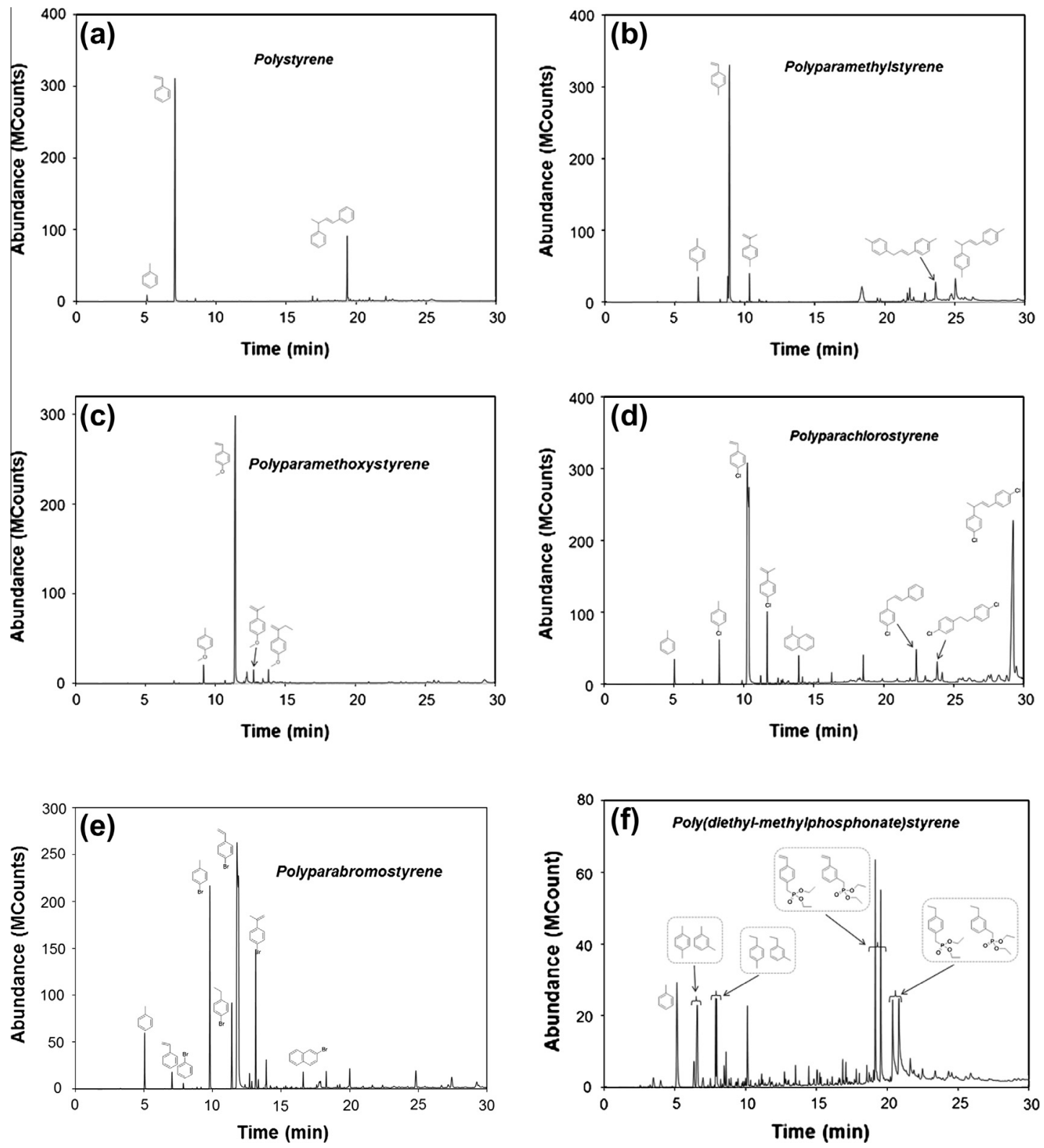

Fig. 9. Py-GC/MS analyses of various modified polystyrenes at $600{ }^{\circ} \mathrm{C}$.

aromatic molecules. It should be recalled that these halogenated polystyrenes need a higher temperature for complete combustion in PCFC. Therefore it can be confirmed that the presence of halogenated groups protects the gases against combustion (flame inhibition effect).

PS-P pyrolysis exhibits a complex spectrum with many peaks, and some of them correspond to products of depolymerization. Phosphonated styrenic molecules with a substitution in the meta or para position are observed (the phosphonated polystyrene used in this study was obtained by polymerization of a mixture of diethyl 3-vinylbenzylphosphonate and diethyl 4-vinylbenzylphosphonate). Some intensive peaks correspond to aromatic products without phosphorus. It should be noticed also that this phosphonated polystyrene undergoes strong charring. Therefore, it is probable that a significant fraction of the phosphorus remains in the condensed phase. The presence of some phosphonated molecules in the gaseous phase after pyrolysis is not contradictory to the well-accepted mode of action of phosphorus compounds in the condensed phase (char promotion).
It must be kept in mind that the phosphonated polystyrene decomposes in two well-separated steps. A single analysis at $600{ }^{\circ} \mathrm{C}$ does not allow the separation of gases released by the two steps. Therefore, Py-GC/MS analyses were performed successively on the same sample at $400{ }^{\circ} \mathrm{C}$ (i.e., at a temperature higher than the first step) and then at $600{ }^{\circ} \mathrm{C}$ (i.e., at a temperature higher than the second step). According to EHC values and combustion efficiency curves, it was concluded that the composition of gases released during the two steps is significantly different. Figure 10 shows the Py-GC/MS results, which confirm this point. As expected, very different molecules are released during the two steps. During the first step, phosphonated styrenic molecules are the main products released, while nonphosphonated aromatic molecules are released during the second step. This result is in good agreement with Dumitrascu and Howell [16] and Tai et al. $[17,18]$. In these works, copolymers of styrene and phosphonated styrenes with various structures were synthesized and studied. In many cases, two peaks of decomposition were observed. The first one, at low temperature, was attributed to the decomposition 

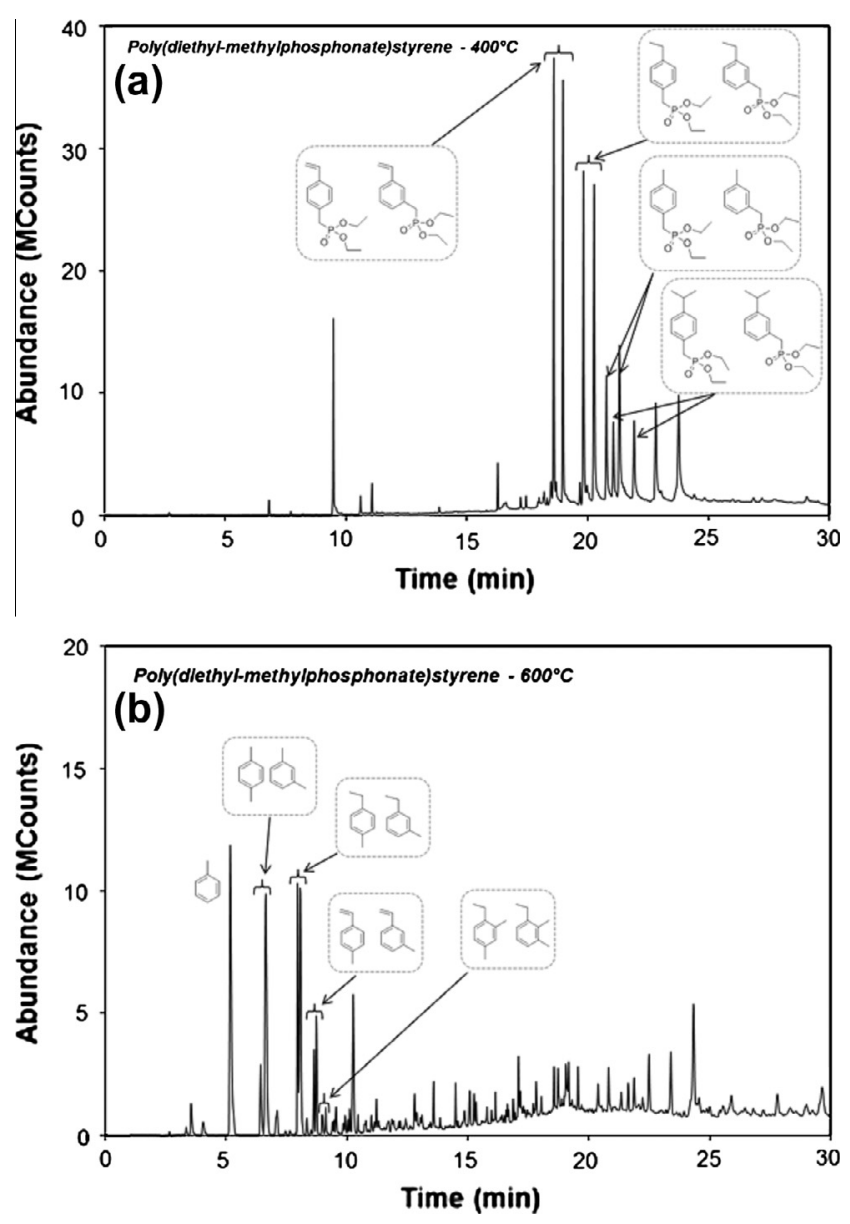

Fig. 10. Py-GC/MS analyses of PS-P at $400{ }^{\circ} \mathrm{C}$ (top) and $600{ }^{\circ} \mathrm{C}$ (bottom).

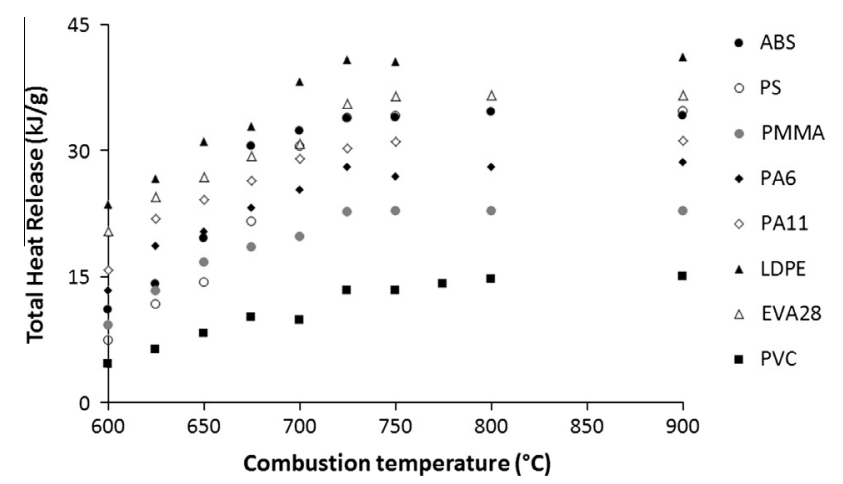

Fig. 11. Total heat release of various commercial polymers measured by PCFC at different combustion temperatures.

of the phosphonated comonomer. This peak was much lower than the one that we observed for PS-P because the content of the phosphonated comonomer was not higher than $20 \mathrm{wt} \%$. In particular, Dumitrascu and Howell have studied a copolymer containing $5-20 \mathrm{wt} \%$ of the (diethylmethylphosphonate)styrene. The authors observed a small peak of heat release rate between 300 and $375^{\circ} \mathrm{C}$ in PCFC, which was attributed to the release of phosphonate units.

The low EHC associated with the second peak is surprising because the molecules released during this step are toluene, methylstyrene, etc., which should exhibit a much higher effective heat of complete combustion. For example, the effective heat of complete combustion calculated from the atomic composition is $41 \mathrm{~kJ} / \mathrm{g}$ for toluene (see [19] for a description of the calculation). This result has not been explained yet.

\subsection{Combustion efficiency of series B: a phenomenological modeling to describe the combustion of pyrolysis gases}

THR of eight commercial polymers measured by PCFC for various combustion temperatures are presented in Fig. 11. The THR for complete combustion is different for all polymers in each case. As previously, Fig. 12 was plotted to study specifically the combustion efficiency. It appears that these polymers could be separated in three groups according to the shape of the combustion efficiency curve. The first group gathers the aliphatic polymers containing $C$, $\mathrm{H}, \mathrm{O}$, and $\mathrm{N}$. These polymers show complete combustion when the combustion temperature is higher than $725^{\circ} \mathrm{C}$. Below this critical temperature, combustion efficiency decreases progressively. Its value is still 0.8 at $675^{\circ} \mathrm{C}$ and close to $0.6-0.7$ at $625^{\circ} \mathrm{C}$. The second group gathers the styrenic polymers PS and ABS. As for the first group, these polymers exhibit complete combustion above $725^{\circ} \mathrm{C}$. Nevertheless, below this temperature, the combustion efficiency decreases drastically. At $675^{\circ} \mathrm{C}$, its value is 0.6 , and it is close to 0.4 at $650{ }^{\circ} \mathrm{C}$. The last group corresponds to PVC, i.e., a halogenated polymer. The curve is more complex and shows two stages, as for $\mathrm{PS}-\mathrm{Br}$ from series A. Combustion efficiency starts decreasing slowly below $800^{\circ} \mathrm{C}$. At $725^{\circ} \mathrm{C}$, the value is 0.83 . Below this temperature, the combustion efficiency decreases faster (close to 0.5 at $650{ }^{\circ} \mathrm{C}$ ).

Most of the polymers considered undergo degradation in one step during the pyrolysis. Nevertheless, EVA and PVC exhibit two peaks of degradation. As for PS-P, the gases formed during the two degradation steps have different combustion efficiencies. For example, the peak of HRR corresponding to acetic acid released during the first degradation step of EVA totally disappears when the combustion temperature is lower than $600{ }^{\circ} \mathrm{C}$. This observation points out that acetic acid needs a combustion temperature higher than that of the gases released from the second step (pyrolysis of polyenes formed after release of acetic acid). Nevertheless, the THR values associated with the first peak are too low to be measured accurately. Similarly, the THR values associated with the different degradation steps of PVC are too low.

For most of the tested polymers from series A and B, the combustion efficiency curve is relatively simple. The combustion efficiency is equal to 1 above a critical temperature (close to $700{ }^{\circ} \mathrm{C}$ ) and exhibits a sigmoidal decrease below this temperature. By analogy with crystallization curves (the Avrami model), the equation

$1-X(T)=\exp \left(-A \times T^{n}\right)$,

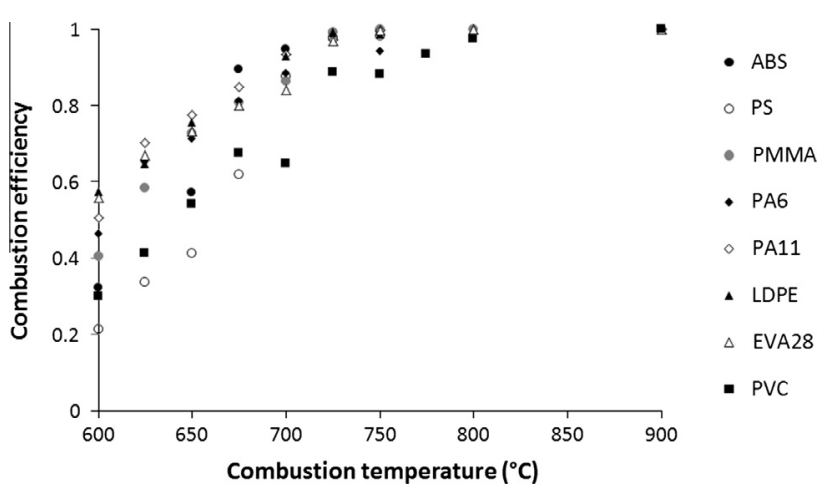

Fig. 12. Combustion efficiency of various commercial polymers measured by PCFC at different combustion temperatures. 
was proposed to model the combustion efficiency curves. Plotting $\operatorname{Ln}(-\operatorname{Ln}(1-X(T)))$ versus $\operatorname{Ln}(T)$ makes it possible to determine the two parameters $n$ and $A$ :

$$
\operatorname{Ln}(-\operatorname{Ln}(1-X(T)))=n \times \operatorname{Ln} T+\operatorname{Ln} A .
$$

At least five experimental points between 600 and $750{ }^{\circ} \mathrm{C}$ were taken into account to fit these parameters (at higher temperatures, combustion efficiency is too close to 1 ). Halogenated polymers (PS$\mathrm{Br}, \mathrm{PS}-\mathrm{Cl}$, and $\mathrm{PVC}$ ) were not considered, since their combustion efficiency curves show two stages. Two sets of parameters were calculated for PS-P, corresponding to the first and second pyrolysis steps.

Figure 13 shows graphically the calculation of $n$ and $A$ for PS. For all the samples, the correlation coefficient $R^{2}$ is higher than .95 (except for the first pyrolysis peak of PS-P: $R^{2}=0.93$ ).

Figure 14 shows the variation of $n$ versus $\operatorname{Ln} A$ for the different polymers studied. Surprisingly, a linear relation between $n$ and $\operatorname{Ln} A$ is highlighted indicating a strong correlation between both parameters. Presently, no physical sense could be attributed to $A$ and $n$. Lyon et al. have presented another approach to evaluating the kinetic parameters for the thermal oxidation of fuels in excess of oxygen $[15,20,21]$. This approach is more valuable since it allows calculating "physical" parameters. But it needs isothermal experiments which are not possible using PCFC. Nevertheless, these results show that the knowledge of $n$ (or alternatively $A$ ) is enough to describe precisely the combustion efficiency curve of the polymers under consideration. A high value for the $n$ parameter corresponds to a fast decrease in combustion efficiency below the critical temperature (close to $700{ }^{\circ} \mathrm{C}$ ). It could be noticed that the calculated parameters are consistent with the chemical structure of the studied polymers. For example, PA6 and PA11 exhibit very similar $n$ and $A$ values. EVA28 and LDPE show the lower $n$ values. Styrenic polymers exhibit also similar parameters (high $n$ values), except PS-P. The parameters for the second peak of this polymer are close to (but lower than) those of styrenic polymers, while

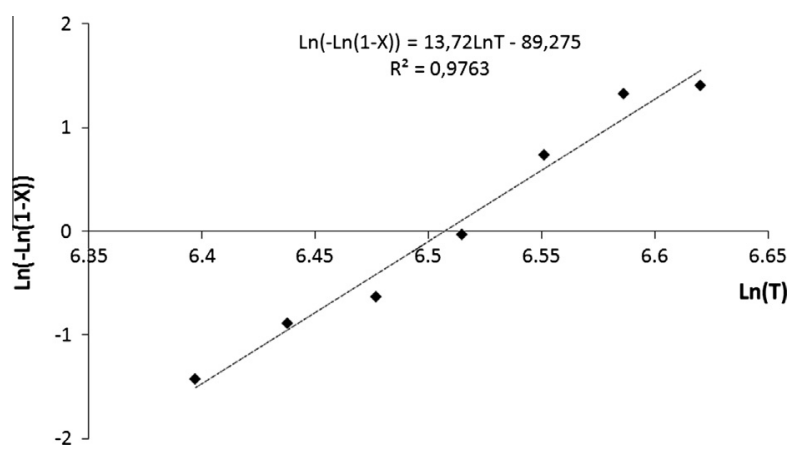

Fig. 13. Calculation of $n$ and $A$ parameters for PS.

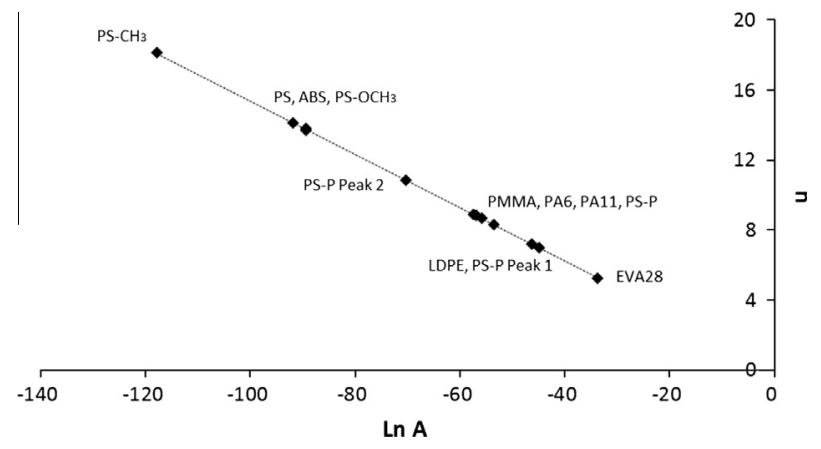

Fig. 14. $n=f(\operatorname{Ln} A)$ for the polymers under consideration.

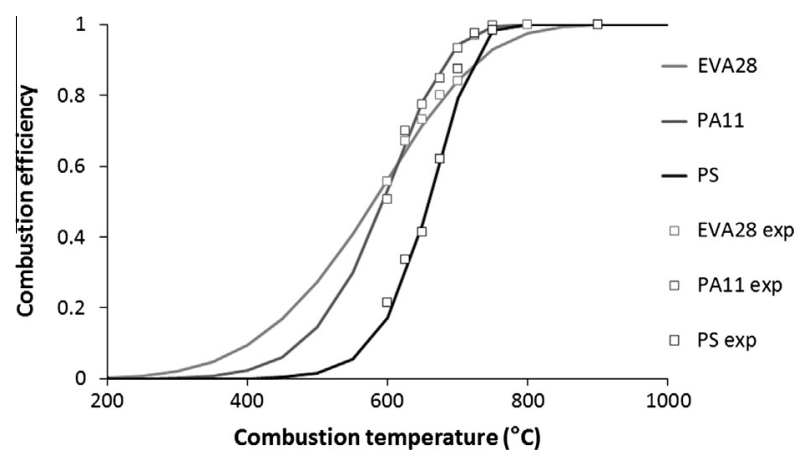

Fig. 15. Modeling curves and experimental data for PA11, PS, and EVA28.

the parameters for the first peak are close to those of LDPE. Very noticeably, this result is in good agreement with Py-GC/MS analyses. Indeed nonsubstituted aromatic molecules are released during the second step of degradation. These molecules are close to those for the molecules released during the polystyrene pyrolysis.

Figure 15 shows the modeling curves for PS, EVA28, and PA11. These curves were drawn from Eq. (1) and the parameters $n$ and $A$ calculated previously. Experimental points are also plotted for these three polymers. Very good agreement has been obtained between the modeling curve and experimental points in the three cases. These curves should be very useful in understanding some phenomena as ignition. Ignition occurs when fuels can be oxidized in the gaseous phase. This oxidation requires oxygen and heat. According to Fig. 15, it appears that a very low temperature $\left(400^{\circ} \mathrm{C}\right)$ is sufficient to start the combustion of a significant amount of the gases released by the pyrolysis of EVA28. Combustion efficiency is equal to 0.1 at this temperature. In contrast, a higher temperature $\left(550{ }^{\circ} \mathrm{C}\right)$ is required to allow similar combustion efficiency for PS. While all gases released by PS are burnt at $700{ }^{\circ} \mathrm{C}$, the combustion efficiency of EVA28 is not equal to 1 at this temperature (according to the modeling curve, but experimental combustion efficiency is closer to 1 in this case). Similar inversion could be observed between EVA28 and PA11 curves but at lower temperature (inversion point is close to $600{ }^{\circ} \mathrm{C}$ ). In contrast, when PS and PA11 curves are compared, combustion efficiency is higher for PA11 whatever the temperature.

\subsection{Combustion efficiency of series C: correlations between PCFC and cone calorimeter tests}

Series $C$ was tested to evaluate the flame inhibition when the flame retardants were not grafted onto the macromolecular backbone but physically incorporated into the matrix. Moreover, these formulations (and some polymers from series B) were tested with a cone calorimeter apparatus to identify possible correlations between PCFC and cone calorimeter results. Three flame retardant systems were studied: TBBA, TBBA/ $\mathrm{Sb}_{2} \mathrm{O}_{3}$, and APP. TBBA is known as a flame retardant acting in the gaseous phase. Synergy between TBBA and antimony trioxide is also well known. APP is a flame retardant acting in the condensed phase as a charring promoter. Moreover, the release of ammonia from APP also leads to a dilution of the gaseous phase. Flame inhibition is not considered as one of the modes of action of this additive, but it was reported that some phosphorus compounds could act as flame inhibitors. Braun et al. [22] has studied the flame retardancy of epoxy resins containing phosphine oxide, phosphinate, phosphonate, and phosphate in their structure. The authors concluded that phosphorus compounds (particularly phosphine oxide) also act as flame inhibitors. Nevertheless, their conclusions were based on the decrease in EHC in the cone calorimeter when these compounds were incorporated. 
EHC could be reduced not only because of a decrease in combustion efficiency but also because phosphorus gases release intrinsically less heat even if the combustion is complete. Hergenrother et al. [23] studied similar epoxy resins with curing agents containing phosphorus. Combustion efficiency was calculated as the ratio between EHC in fire calorimeter tests and EHC calculated in PCFC at a combustion temperature of $900{ }^{\circ} \mathrm{C}$. Combustion efficiency was found to be 0.7 without phosphorus. Almost all phosphoruscontaining samples exhibited higher combustion efficiency. But three samples exhibited significantly lower combustion efficiency (0.55-0.6). In a comprehensive review [24], Schartel noted the flame inhibition of aluminum tris-diethylphosphinate $\left(\mathrm{AlPO}_{2}\right)$ in PBT/GF (glass fiber) composites. This assertion is based on the calculation of combustion efficiency. The combustion efficiency of $\mathrm{PBT} / \mathrm{GF}$ is 0.98 . The incorporation of $6.3 \mathrm{wt} \%$ of $\mathrm{AlPO}_{2}$ decreases this value to 0.64 .

Figures 16-18 show the combustion efficiency of ABS filled with TBBA, TBBA/ $\mathrm{Sb}_{2} \mathrm{O}_{3}$, and APP. ABS filled with TBBA exhibits a combustion efficiency curve similar to that of PS-Br (Fig. 16). Combustion efficiency starts decreasing at $800^{\circ} \mathrm{C}$, in particular when high amounts of TBBA are incorporated. At $725^{\circ} \mathrm{C}$, combustion efficiency is decreased to $0.8-0.85$, while ABS shows complete combustion in the absence of TBBA. However, at a low combustion temperature $\left(650^{\circ} \mathrm{C}\right.$ or lower), no great difference is observed. It should be noted that combustion efficiency is lower for ABS filled with $15.6 \mathrm{wt} \%$ of TBBA than for ABS filled with $31 \mathrm{wt} \%$ of TBBA (in particular between 675 and $725^{\circ} \mathrm{C}$ ). A simple explanation is as follows: The combustion efficiency curve of ABS filled with $31 \mathrm{wt} \%$ of TBBA does not exhibit any plateau at high combustion temperature, which could indicate that the combustion is not complete even at $900{ }^{\circ} \mathrm{C}$, as for PS-Br. But this result may also be consistent with the saturation effect of the chemical component of

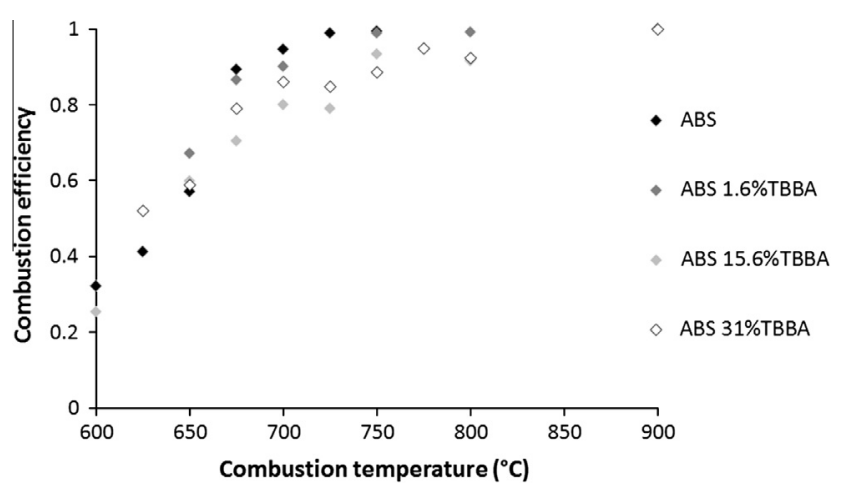

Fig. 16. Combustion efficiency of ABS filled with TBBA measured in PCFC at different combustion temperatures.

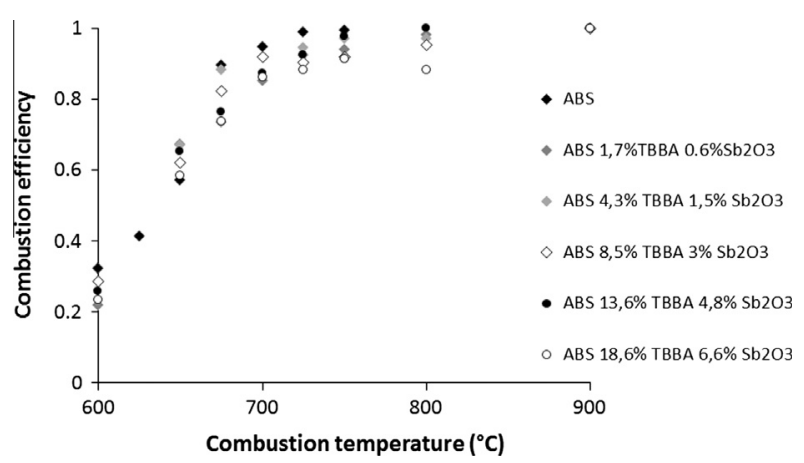

Fig. 17. Combustion efficiency of ABS filled with TBBA and $\mathrm{Sb}_{2} \mathrm{O}_{3}$ measured in PCFC at different combustion temperatures.

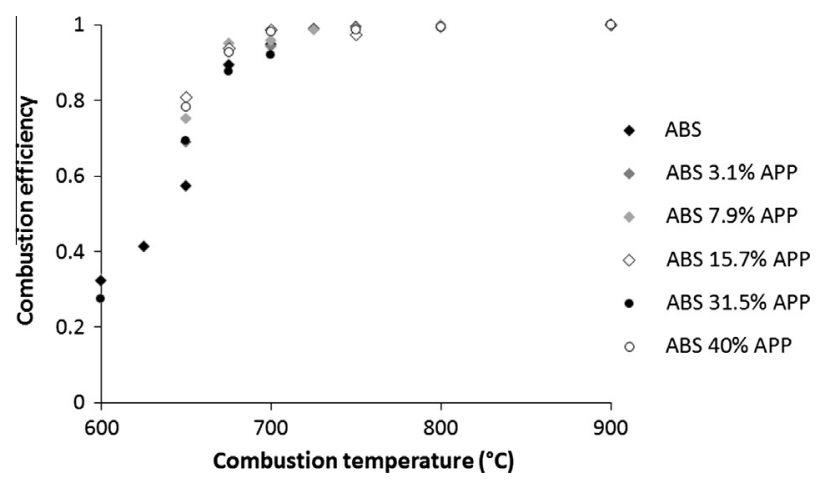

Fig. 18. Combustion efficiency of ABS filled with APP measured in PCFC at different combustion temperatures.

flame inhibition when the content of the flame retardant increases $[2,3]$. At the same time, smaller amounts of fuels are released because TBBA partially replaces ABS. The combination of these two tendencies leads to the increase of combustion efficiency. Nevertheless, total heat release is lower for ABS filled with $31 \mathrm{wt} \%$ of TBBA because of the smaller amount of fuels $(23.8$ and $18.8 \mathrm{~kJ} / \mathrm{g}$ at 900 and $675{ }^{\circ} \mathrm{C}$ for $31 \mathrm{wt} \%$ of TBBA versus 29.7 and $20.9 \mathrm{~kJ} / \mathrm{g}$ at the same temperatures for $15.6 \mathrm{wt} \%$ of TBBA). The measurement of the combustion efficiency in PCFC appears as a useful method of optimizing the flame inhibition effect of a flame retardant.

The combustion efficiency of ABS filled with the system TBBA/ $\mathrm{Sb}_{2} \mathrm{O}_{3}$ is also lower than that of pure ABS in the temperature range $675-800{ }^{\circ} \mathrm{C}$ (Fig. 17). As reported previously for PS-Br and ABS filled with $31 \mathrm{wt} \%$ TBBA, it should be noted that the combustion of ABS filled with $18.6 \mathrm{wt} \%$ TBBA and $6.6 \mathrm{wt} \% \mathrm{Sb}_{2} \mathrm{O}_{3}$ may be not complete while the curve does not exhibit any plateau at high combustion temperature. As for TBBA, combustion efficiency of all formulations with $\mathrm{TBBA} / \mathrm{Sb}_{2} \mathrm{O}_{3}$ seems to be similar below $650{ }^{\circ} \mathrm{C}$. It should be noted that combustion efficiency is higher for TBBA/ $/ \mathrm{Sb}_{2} \mathrm{O}_{3}$ than for TBBA at similar FR content (TBBA content is lower in the TBBA/ $/ \mathrm{Sb}_{2} \mathrm{O}_{3}$ system because of its partial replacement by $\mathrm{Sb}_{2} \mathrm{O}_{3}$ ). The synergy between TBBA and $\mathrm{Sb}_{2} \mathrm{O}_{3}$ does not seem relevant according to these data. Antimony trioxide is believed to enhance the flame inhibition by decomposing and volatilizing bromine compounds at lower temperatures [12,25]. Many works report that antimony trioxide leads to a two-step decomposition in brominated styrenic polymers $[25,26]$. Jakab et al. [25] identified that the first step, at low temperature, corresponds to the release of $\mathrm{SbBr}_{3}$, brominated organic compounds, water, and styrene (the studied matrix was hiPS). In PCFC, this step should hardly be detected, since most of the gases are not (or are little) combustible. Indeed, we observed a small shoulder below $400{ }^{\circ} \mathrm{C}$ for some $A B S$ containing sufficient amounts of $\mathrm{TBBA} / \mathrm{Sb}_{2} \mathrm{O}_{3}$ (not shown). This shoulder was also observed without a synergist, but to a smaller extent. Flame inhibition from bromine should be most efficient if bromine is released during the decomposition of ABS. While the sample is heated according to a linear heating rate in PCFC, maybe bromine is volatilized too early in the presence of antimony trioxide, and its efficiency is decreased.

Whatever the APP content in ABS, no decrease in combustion efficiency is observed (Fig. 18). Combustion efficiency is very close to the value for pure ABS above $675^{\circ} \mathrm{C}$. Moreover, below this temperature, combustion efficiency seems to be higher for ABS filled with APP. This behavior could not be explained clearly. This may be due to measurement uncertainties. But it could be remarked that PS-P also exhibits significantly higher combustion efficiency at low temperature than other modified polystyrenes. In all cases, the results show clearly that APP does not exhibit any flame inhibition action. 

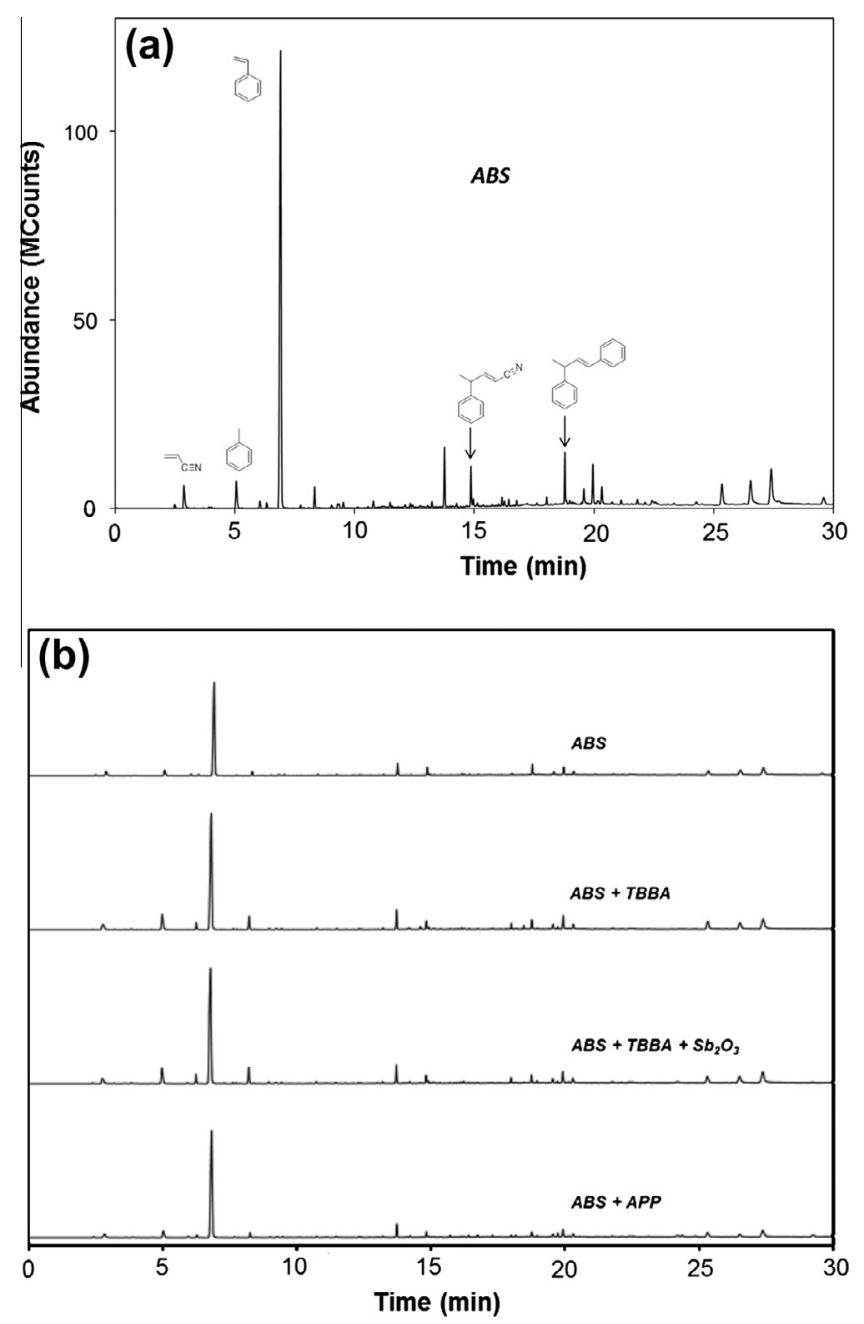

Fig. 19. Py-GC/MS analyses of pure and flame retarded $A B S$ at $600{ }^{\circ} \mathrm{C}$.

Py-GC/MS analyses were performed on ABS and ABS filled with $31.5 \mathrm{wt} \%$ of APP (10 wt\% of P), $17 \mathrm{wt} \%$ of TBBA ( $10 \mathrm{wt} \%$ of $\mathrm{Br}$ ), and $8.5 \mathrm{wt} \%$ of TBBA with $3 \mathrm{wt} \%$ of $\mathrm{Sb}_{2} \mathrm{O}_{3}$ ( $5 \mathrm{wt} \%$ of $\mathrm{Br}$ ) to evaluate the changes in the gaseous phase (Fig. 19). Products from pyrolysis of styrenic polymers containing brominated flame retardants with and without antimony trioxide have been extensively studied $[25,27,28]$. Many brominated compounds are released, but the Py-GC/MS chromatogram is dominated by the products from the decomposition of the matrix [25]. The accurate study of the pyrolysis products is out of the scope of this article, but it is clear from Fig. 19 that the decomposition of the ABS matrix is not (or is little) modified when flame retardants are incorporated. This result confirms that the combustion efficiency in the presence of TBBA does not decrease, because the gases released from pyrolysis would be different in nature (and would exhibit another combustion efficiency profile). The combustion efficiency could be attributed to flame inhibition (or flame poisoning). This flame inhibition occurs when $\mathrm{HBr}$ from debromination of TBBA reacts with highly reactive radicals $\mathrm{OH}^{\cdot}$ to form more stable radicals. While $\mathrm{OH}^{*}$ radicals are involved in the oxidation mechanism of fuels, their trapping leads to incomplete combustion.

Correlations between the cone calorimeter and the PCFC are still a challenge. As explained in the Introduction, three reasons could lead to noncorrelated results between the two experimental techniques. Combustion efficiency is one of these reasons, since the PCFC test is generally performed at a high combustion temperature $\left(900^{\circ} \mathrm{C}\right.$ ), which ensures complete combustion. In contrast, combustion conditions are not controlled during a cone calorimeter test, and therefore combustion efficiency could only be calculated a posteriori. Flame retarded ABS and some polymers from series $\mathrm{B}$ were tested in a cone calorimeter test at irradiance equal to $50 \mathrm{~kW} /$ $\mathrm{m}^{2}$. The combustion efficiency in the cone calorimeter could be calculated using the equation

$\chi(T)=\left(\Delta \mathrm{O}_{2}(\right.$ cone $\left.)\right) /\left(\Delta \mathrm{O}_{2}\left(\mathrm{PCFC}\right.\right.$ at $\left.\left.900^{\circ} \mathrm{C}\right)\right)$,

where $\Delta \mathrm{O}_{2}$ (cone) $T$ is the mass or volume of oxygen consumed during cone calorimeter test $T$, and $\Delta \mathrm{O}_{2}\left(\mathrm{PCFC}\right.$ at $900^{\circ} \mathrm{C}$ ) is the oxygen consumed by complete combustion of the pyrolysis gases at $T=900^{\circ} \mathrm{C}$ in the PCFC.

Heat release is measured in the cone calorimeter according to the oxygen depletion method. Therefore we calculated the combustion efficiency using the equation

$$
\chi(\text { cone })=(\operatorname{THR}(\text { cone })) /\left(\operatorname{THR}\left(\operatorname{PCFC} \text { at } 900{ }^{\circ} \mathrm{C}\right)\right) \text {, }
$$

which is equivalent to Eq. (5A). THR in the cone calorimeter is usually calculated in $\mathrm{MJ} / \mathrm{m}^{2}$. Knowing the surface area and the initial mass of the sample, THR could easily be calculated in $\mathrm{kJ} / \mathrm{g}$ (as in Eq. (5B)). It should be also noticed that mass residues in the cone and in the PCFC are similar in most cases. Discrepancy is observed only when polymers or fillers with high thermal stability are not fully degraded in the cone calorimeter [7]. That is not the case here. Discrepancy could also occur when char undergoes thermo-oxidation, mainly after flame-out [29]. But in this study, THR at flame-out has been considered. Therefore, the combustion efficiency calculated according to Eq. (3) is very close to the combustion efficiency calculated considering EHC (we have checked that the two methods lead to similar values of combustion efficiency).

Isoconversion temperature was defined as the combustion temperature in the PCFC needed to obtain the same combustion efficiency as in the cone calorimeter test. In each case, its value was calculated by linear interpolation between two experimental measurements in PCFC. Figure 20 shows the evolution of the isoconversion temperature versus the combustion efficiency in cone calorimeter. Surprisingly most of the formulations exhibit close values for isoconversion temperature (between 650 and $700{ }^{\circ} \mathrm{C}$ ). Moreover, a rough tendency could be drawn between this parameter and the combustion efficiency. For low combustion efficiency, the isoconversion temperature is lower than $650{ }^{\circ} \mathrm{C}$ (between 630 and $650{ }^{\circ} \mathrm{C}$ ). For high combustion efficiency (close to 1 ), the isoconversion temperature could increase to $720^{\circ} \mathrm{C}$. Of course the combustion conditions are very different between the cone calorimeter and the PCFC. The temperature of the diffusion flame in the cone calorimeter is $1800-2000 \mathrm{~K}$ and the residence time of gases in this flame is on the order of milliseconds. In the PCFC,

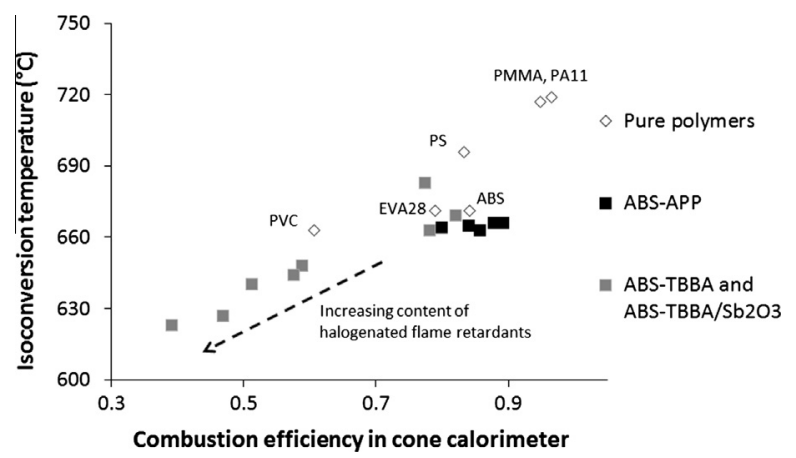

Fig. 20. Isoconversion temperature versus combustion efficiency in the cone calorimeter (irradiance $50 \mathrm{~kW} / \mathrm{m}^{2}$ ) for flame retarded ABS and pure polymers. 
the thermal oxidation occurs under premixed nonflaming conditions and the residence time of gases in the combustor is close to $10 \mathrm{~s}$ (as said in the Experimental section). Therefore the isoconversion temperature is only a parameter that allows comparing cone calorimeter and PCFC results. It is not the true temperature of the combustion zone in the cone calorimeter.

It could be noted that the isoconversion temperature does not change when APP is incorporated into ABS. In contrast, the addition of TBBA or TBBA $/ \mathrm{Sb}_{2} \mathrm{O}_{3}$ leads to a decrease in combustion efficiency and isoconversion temperature. PVC, as a halogenated polymer, exhibits also a relatively low isoconversion temperature, in comparison to other pure polymers.

Our results also allow prediction of the combustion efficiency in the cone calorimeter test using PCFC tests. Two analyses at combustion temperatures equal to 650 and $700{ }^{\circ} \mathrm{C}$ allow determining the lower and the upper limits of combustion efficiency. Nevertheless, in this range, combustion efficiency could change drastically for many formulations, and therefore the prediction is not so precise. For example, these lower and upper limits are 0.41 and 0.88 , respectively, for PS. In contrast, for PA6, the lower and upper limits are 0.72 and 0.88 , respectively, which allows quite a good prediction.

The peak of the heat release rate at the isoconversion temperature in the PCFC was calculated for all flame-retarded ABS. As for the isoconversion temperature, these data were determined by linear interpolation between two experimental pHRR (for example, the pHRR at an isoconversion temperature equal to $660^{\circ} \mathrm{C}$ was calculated by interpolation between pHRR measured at 650 and $675^{\circ} \mathrm{C}$ ). All formulations were decomposed in one step. In some cases, a very small shoulder at low temperature was observed. This shoulder was neglected. In a previous work [30], an empirical method was proposed for comparing cone calorimeter and PCFC data. Two parameters were defined as follows:

\section{$R 1=(\mathrm{pHRR}$ (flame retarded polymer) in the PCFC) $/($ pHRR(pure polymer) in the PCFC),}

\section{$R 2=($ pHRR(flame retarded polymer $)$ in the cone calorimeter $)$ $/$ (pHRR(pure polymer) in the cone calorimeter).}

According to many experimental results, $R 1$ is always equal to or higher than $R 2$. This means that the decrease in pHRR is always stronger in the cone calorimeter than in the PCFC when a flame retardant is incorporated. Indeed, in the PCFC, very small samples (with a weight as low as $2 \mathrm{mg}$ ) are tested. Therefore, the barrier effect is negligible because no insulating thick layer could be formed. We proposed that the barrier effect is not a significant mode of action of a flame retardant additive when $R 1=R 2$. In contrast, when $R 2<R 1$ (i.e., when the decrease in pHRR is stronger in the cone calorimeter than in the PCFC), it could be concluded that the barrier effect is efficient in the cone calorimeter. In this first work, PCFC analyses were performed under standard conditions (combustion temperature equal to $900{ }^{\circ} \mathrm{C}$ ). Of course, this empirical approach is only possible if the thermal stabilities in the PCFC and the combustion efficiencies in the cone calorimeter of both pure and flame retarded polymers (the two other sources of noncorrelation between the cone calorimeter and the PCFC) are similar. These conditions were fulfilled. More details and examples could be found elsewhere [30-33].

Figure 21 shows this $R 1-R 2$ graph for flame-retarded ABS at two combustion temperatures in the PCFC: $900^{\circ} \mathrm{C}$ and the isoconversion temperature (this temperature was calculated for each formulation). In the case of ABS filled with APP, $R 2$ is lower than $R 1$ for both temperatures. The fact that $R 2$ is lower than $R 1$ is typical of a barrier effect. In this case the barrier is due to the char formed in the presence of the phosphorus compound. $R 2$ is lower than

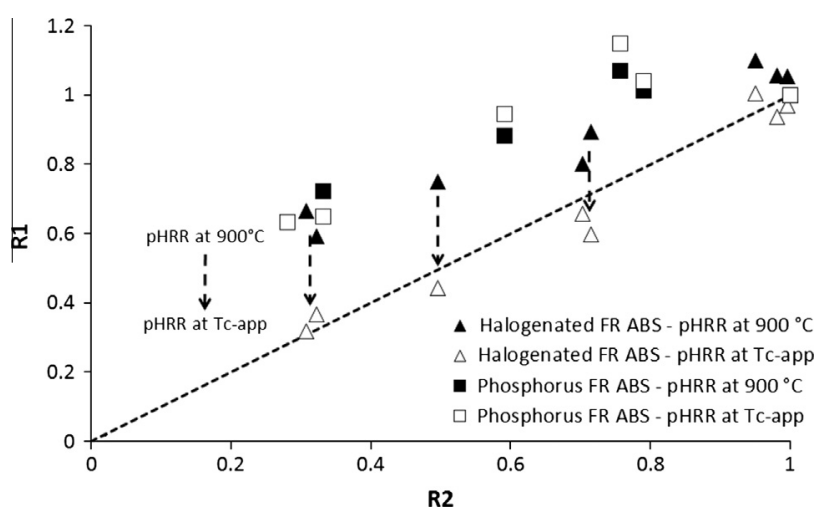

Fig. 21. $R 1-R 2$ graph for flame-retarded $A B S$ at two combustion temperatures in the PCFC.

$R 1$ for both combustion temperatures because the combustion efficiency curves are similar for ABS and ABS filled with APP. Therefore, the ratio between $R 1$ and $R 2$ is the same whatever the combustion temperature in the PCFC.

In contrast, for ABS filled with brominated compounds, $R 2$ was lower than $R 1$ when PCFC analyses were performed at $900{ }^{\circ} \mathrm{C}$. According to our previous analysis, this would mean that these flame-retarded ABS formulations exhibit a barrier effect, while no residue was formed in the cone calorimeter. Of course this conclusion is wrong. The reason is that these formulations exhibited very different combustion efficiencies in the cone calorimeter test and these differences could not be taken into account in the PCFC when the combustion was complete (at $900^{\circ} \mathrm{C}$ ). When PCFC analyses were performed at the isoconversion temperature, $R 2$ becomes much closer to $R 1$ and the barrier effect vanished (as shown by the plotted arrows in Fig. 21). Since the decrease of pHRR is similar in the cone calorimeter and the PCFC in the absence of a barrier effect, it should be possible to predict the pHRR of a flame-retarded formulation in the cone calorimeter test using PCFC if the isoconversion temperature is known. It must be recalled that this temperature seems to range between 650 and $700{ }^{\circ} \mathrm{C}$ in most cases.

\section{Conclusions}

In this article, a new method was proposed for studying the flame inhibition effect of a flame retardant reactive or additive compound using PCFC. The flame inhibition effect of chlorinated and brominated compounds was confirmed, since the combustion efficiency decreases from $750-800^{\circ} \mathrm{C}$ for polymers containing these elements. In contrast, other formulations exhibit combustion efficiency close to 1 up to $700-725^{\circ} \mathrm{C}$. PCFC appears as a useful method to optimize the flame inhibition effect of a flame retardant, since very small amounts of sample are needed and combustion conditions can be monitored perfectly. Nevertheless, for some halogenated polymers, the combustion could be not complete at $900{ }^{\circ} \mathrm{C}$. In this case, the method leads to overestimation of the combustion efficiency at any temperature lower than $900^{\circ} \mathrm{C}$.

A phenomenological equation was proposed to model the combustion efficiency versus the temperature of combustion. Only one parameter seems necessary to describe the combustion efficiency curves of the nonhalogenated formulations. For halogenated formulations, at least two steps were observed, and correct modeling needs more experimental points.

Correlations between the cone calorimeter and the PCFC were established. In particular, a new parameter called "isoconversion temperature" was defined. Its value is found close to $650-700{ }^{\circ} \mathrm{C}$ for most of the tested formulations, even if the combustion effi- 
ciencies in the cone calorimeter test are very different. To evaluate the effective heat of combustion in the cone calorimeter using the PCFC, carrying out the PCFC test in the combustion temperature range $650-700^{\circ} \mathrm{C}$ is recommended. Indeed, some pure polymers (such as PVC) could exhibit a relatively low combustion efficiency in the cone calorimeter, and therefore a PCFC test at $900{ }^{\circ} \mathrm{C}$ should overestimate the effective heat of combustion significantly. But unfortunately, the combustion efficiency changes strongly in this temperature range. Therefore the prediction of the combustion efficiency in the cone calorimeter using the PCFC could not be accurate.

Moreover, when no barrier effect is efficient, the decrease of pHRR in the cone calorimeter when a flame retardant additive is incorporated could be predicted according to the decrease of pHRR in the PCFC. In this case, PCFC analysis should be carried out at a combustion temperature corresponding to the isoconversion temperature when the flame retardant has a flame inhibition action (such as halogenated additives).

Finally, our results also confirm that the PCFC is a powerful tool for studying various aspects of the flammability of a polymer.

\section{Acknowledgment}

We thank Claire Negrell-Guirao from IAM-Institut C. Gerhardt (Montpellier) for providing the PS-P sample.

\section{References}

[1] V. Babushok, W. Tsang, Combust. Flame 123 (2000) 488-506.

[2] T. Noto, V. Babushok, D.R. Burgess Jr., Hamins A, Tsang W, A. Miziolek, in: 26th Symposium on Combustion/The Combustion Institute, 1996, pp. 1377-1383.

[3] T. Noto, V. Babushok, A. Hamins, W. Tsang, Combust. Flame 112 (1998) $147-$ 160.

[4] V. Babushok, W. Tsang, G.T. Linteris, D. Reinelt, Combust. Flame 115 (1998) $551-560$.

[5] R.E. Lyon, R.N. Walters, J. Anal. Appl. Pyrol. 71 (2004) 27-46.
[6] A.B. Morgan, M. Galaska, Polym. Adv. Technol. 19 (2008) 530-546.

[7] J.M. Cogen, T.S. Lin, R.E. Lyon, Fire Mater. 33 (2009) 33-50.

[8] H. Lu, C.A. Wilkie, Polym. Degrad. Stab. 95 (2010) 564-571.

[9] R.E. Lyon, R.N. Walters, S.I. Stoliarov, Polym. Eng. Sci. 47 (2007) 1501-1510.

[10] B. Schartel, K.H. Pawlowski, R.E. Lyon, Thermochim. Acta 462 (2007) 1-14.

[11] I. Finberg, Y. Bar Yaakov, P. Georlette, Polym. Degrad. Stab. 64 (1999) 465-470.

[12] J. Kaspersma, C. Doumen, S. Munro, A.M. Prins, Polym. Degrad. Stab. 77 (2002) 325-331.

[13] ASTM D7309, 2011.

[14] C. Huggett, Fire Mater. 4 (1980) 61-65.

[15] R.E. Lyon, R.N. Walters, in: Fire and Materials Conference, San Francisco, CA, January 28-30, 2013.

[16] A. Dumitrascu, B.A. Howell, Polym. Degrad. Stab. 96 (2011) 342-349.

[17] Q. Tai, L. Chen, L. Song, S. Nie, Y. Hu, R.K.K. Yuen, Polym. Degrad. Stab. 95 (2010) 830-836

[18] Q. Tai, L. Song, Y. Hu, R.K.K. Yuen, H. Feng, Y. Tao, Mater. Chem. Phys. 134 (2012) 163-169.

[19] R.N. Walters, S.M. Hackett, R.E. Lyon, Fire Mater. 24 (2000) 245-252.

[20] R.E. Lyon, R.N. Walters, S.I. Stoliarov, J. ASTM Int. 3 (4) (2006) 1-18.

[21] R.N. Walters, R.E. Lyon, in: 40th Meeting of the North American Thermal Analysis Society, Orlando, FL, August 12-15, 2012.

[22] U. Braun, A.I. Balabanovitch, B. Schartel, U. Knoll, J. Artner, M. Ciesielski, M. Doring, R. Perez, J.K.W. Sandler, V. Altstadt, T. Hoffmann, D. Pospiech, Polymer 47 (2006) 8495-8508.

[23] P.M. Hergenrother, C.M. Thompson, J.G. Smith Jr., J.W. Connell, J.A. Hinkley, R.E. Lyon, R. Moulton, Polymer 46 (2005) 5012-5024.

[24] B. Schartel, Materials 3 (2010) 4710-4745.

[25] E. Jakab, Md.A. Uddin, T. Bhaskar, Y. Sakata, Y. Sakata, J. Anal. Appl. Pyrolysis 68-69 (2003) 83-99.

[26] G. Grause, J. Ishibashi, T. Kameda, T. Bhaskar, T. Yoshioka, Polym. Degrad. Stab. 95 (2010) 1129-1137.

[27] G. Grause, D. Karatika, J. Ishibashi, T. Kameda, T. Bhaskar, T. Yoshioka, Chemosphere 85 (2011) 368-373.

[28] S.H. Peng, L.Q. Chen, L.B. Li, M.Q. Xie, Proc. Eng. 11 (2011) 349-354.

[29] R.N. Walters, R.E. Lyon, Fire Mater. 27 (2003) 183-194.

[30] R. Sonnier, L. Ferry, C. Longuet, F. Laoutid, F. Friederich, A. Laachachi, J.M. Lopez-Cuesta, Polym. Adv. Technol. 22 (2011) 1091-1099.

[31] L. Tibiletti, C. Longuet, L. Ferry, P. Coutelen, A. Mas, J.J. Robin, J.M. Lopez-Cuesta, Polym. Degrad. Stab. 96 (2011) 67-75.

[32] Y. Quach, N. Cinausero, R. Sonnier, C. Longuet, J.M. Lopez-Cuesta, Fire Mater., in press. doi:http://dx.doi.org/10/1002/fam.1119.

[33] B. Friederich, A. Laachachi, R. Sonnier, M. Ferriol, M. Cochez, V. Toniazzo, D. Ruch, Polym. Adv. Technol., in press. doi:http://dx.doi.org/10/1002/pat.2056. 